March 2018

\title{
Clinical audit to assess delays in chemotherapy administration at daycare oncology center at a tertiary care hospital in Karachi, Pakistan
}

Arifa Aziz

Aga Khan University

Zarka Samoon

Aga Khan University, zarka.samoon@aku.edu

Mohammad Khurshid

Aga Khan University, mohammad.khurshid@aku.edu

Afsheen Feroz

Aga Khan University

Nadia Ayoub

Aga Khan University

See next page for additional authors

Follow this and additional works at: https://ecommons.aku.edu/

pakistan_fhs_mc_med_haematol_oncol

Part of the Hematology Commons, and the Oncology Commons

\section{Recommended Citation}

Aziz, A., Samoon, Z., Khurshid, M., Feroz, A., Ayoub, N., Awan, S., Beg, M. (2018). Clinical audit to assess delays in chemotherapy administration at daycare oncology center at a tertiary care hospital in Karachi, Pakistan. Indian journal of cancer., 55(1), 111-114.

Available at: https://ecommons.aku.edu/pakistan_fhs_mc_med_haematol_oncol/52 
Authors

Arifa Aziz, Zarka Samoon, Mohammad Khurshid, Afsheen Feroz, Nadia Ayoub, Safia Awan, and Madhia Beg 


\author{
Arifa Aziz, Zarka Samoon, Mohammad Khurshid, Afsheen Feroz, Nadia Ayoub, Safia Awan', \\ Madhia Beg \\ Departments of Oncology, ${ }^{1}$ Medicine and ${ }^{2}$ Radiology, Aga Khan University Hospital, Karachi, Pakistan \\ Correspondence to: Dr. Arifa Aziz, E-mail: mailto:arifa.aziz@aku.edu, Dr. Zarka Samoon, E-mail: mailto:zarka.samoon@aku.edu
}

\begin{abstract}
AIM: There were delays reported by patients in chemotherapy administration in daycare oncology. Therefore, we decided to audit all processes which are involved in chemotherapy administration. The objective was to improve our service by decreasing the time between admission and initiation of chemotherapy and identify the reasons for delays. MATERIALS AND METHODS: The audit was conducted in three parts. In Review I, audit tool was developed and information documented of 109 patients receiving chemotherapy at daycare center from April 14 to May $13,2015$. Five processes were assessed out of which delay in initial assessment by the nurse was the only factor identified leading to delay in chemotherapy. Review II was done from March 1 to 31, 2016 of 208 patients after increasing the number of nurses and Review III from June 7 to August 25, 2016 of 287 patients by dividing the initial assessment process at two different areas to decrease delay in initial assessment. RESULTS: Seventy-two percent of patients had their initial assessment done within $15 \mathrm{~min}$ of arrival in daycare in the first audit. In the second part of audit this percentage decreased to $55 \%$, and finally, in the third part of the audit, percentage was improved and increased to $75 \%$ after separating initial assessment process into two areas $(P<0.001$, Kruskal-Wallis test). CONCLUSION: After separating initial assessment process into two different areas, delays in chemotherapy administration were reduced.
\end{abstract}

Key Words: Administration, audit, chemotherapy, delay

\section{Introduction}

Waiting times for initiation of treatment is a major concern for patients in the general medical as well as oncology patient population. ${ }^{[1,2]}$ Extended waiting times affect compliance to clinic appointment and treatment plan. ${ }^{[3-5]}$ Along with this, lack of medical personnel and ambulatory care space also leads to increased waiting time. ${ }^{[6]}$ Prolonged waiting times also result in financial burdens, an area requiring further exploration. ${ }^{[7]}$

There was a consensus by our daycare team of physicians and nurses that patients were not satisfied with the waiting time for chemotherapy administration. In addition, verbal and documented feedback regarding the concern was raised by patients and their families at different times in 2015. Delayed administration can decrease the advantage of chemotherapy, hence affecting outcomes. This has been proven for various cancers including breast and ovarian cancer. ${ }^{[8-10]}$

There is a great responsibility on the chemotherapy unit to give treatment timely and safely. ${ }^{[11]}$ Once patients enter the hospital, they have the right to expect that every effort is made to their care and treatment, which are both safe and effective with no delays. ${ }^{[1]}$

To the best of our knowledge, scientific evidence from our region were lacking regarding factors predisposing to delay in chemotherapy administration. Therefore, we decided to perform internal audit to report and rectify reasons for delays from admission until initiation of chemotherapy. In our study, we aimed to identify factors leading to increase in waiting time for chemotherapy administration.

\begin{tabular}{|l|l|}
\multicolumn{3}{|c|}{ Access this article online } \\
\hline Quick Response Code: & Website: \\
\hline & www.indianjcancer.com \\
\cline { 2 - 2 } & DOI: \\
\cline { 2 - 2 } & 10.4103/ijc.IJC_493_17 \\
\hline
\end{tabular}

\section{Materials and Methods}

Study setting

Aga Khan University Hospital, Karachi, receives cancer patients from all over Pakistan. The daycare center is situated on its main campus. Patients receive intravenous, intrathecal, subcutaneous chemotherapy, hydration, and blood transfusion here. In this 54-bedded daycare unit, patients are adjusted in two shifts and more than 1500 appointments are booked each month. Each day more than eighty adult and pediatric patients are admitted in daycare oncology of Aga Khan University Hospital for chemotherapy and blood transfusions.

\section{Study overview and participants}

To evaluate factors leading to delay in chemotherapy administration, an audit was designed. All patients aged 18 years and above receiving their chemotherapy at Aga Khan University daycare center were enrolled in the study. Chemotherapy included single-day infusion or multiple-day infusions with pumps, both for solid and hematological cancers. Patients were excluded if they were admitted for blood transfusion or intravenous hydration. Nonprobability convenience sampling technique was applied to enroll patients. The study protocol was accepted from the Ethical Review Committee of Aga Khan University Hospital, Karachi, Pakistan, with ERC \#4521-Onc-ERC-16.

\section{Preparation of questionnaire/audit tool sheet}

A questionnaire was prepared by a multidisciplinary team of medical oncologist, daycare staff medical officer, pharmacist,

This is an open access journal, and articles are distributed under the terms of the Creative Commons Attribution-NonCommercial-ShareAlike 4.0 License, which allows others to remix, tweak, and build upon the work non-commercially, as long as appropriate credit is given and the new creations are licensed under the identical terms.

For reprints contact: reprints@medknow.com

How to cite this article: Aziz A, Samoon Z, Khurshid M, Feroz A, Ayoub N, Awan S, et al. Clinical audit to assess delays in chemotherapy administration at daycare oncology center at a tertiary care hospital in Karachi, Pakistan. Indian J Cancer 2018;55:111-4. 
and daycare head nurse. A consensus was made to identify the following mentioned processes and data was collected: (i) arrival time of patient into daycare, (ii) initial assessment time (which includes documentation of height and weight and vital signs [blood pressure, pulse, respiratory rate, and temperature]), (iii) time of order entry in computer physician order entry (CPOE) system, (iv) chemotherapy receiving time from pharmacy, and ( $\mathrm{v}$ ) time of initiation of administration of chemotherapeutic drugs by the nurse. Data were collected using this questionnaire.

\section{Review I to measure current practice}

There were three timelines of the project. The audit started with collaborating with daycare staff medical officer, pharmacist, nurse manager, and head nurse in April 2015 regarding processes which may lead to delay in chemotherapy administration. Five such processes were identified after an extensive discussion and exclusion of few factors based on experience of all the team members: (i) arrival time of patient into daycare, (ii) initial assessment time (which includes documentation of height and weight and vital signs [blood pressure, pulse, respiratory rate, and temperature]), (iii) time of order entry in CPOE system, (iv) chemotherapy receiving time from pharmacy, and (v) time of initiation of administration of chemotherapeutic drugs by the nurse. The time was recorded from the nursing documentation and electronic computer entry. These processes were assessed against their institutional made benchmarks [Table 1]. Time duration of each process was collected and documented on audit questionnaire which was prepared by multidisciplinary team of physician, in charge nurse of daycare oncology and oncology pharmacist. An E-mail was sent to all the daycare nurses and nursing manager of oncology unit in the $1^{\text {st }}$ week of April 2015 regarding the audit. For those without access to E-mail, a copy was displayed in the nursing lounge. Review I was done on 109 patients admitted for chemotherapy at daycare from April 14 to May $13,2015$.

\section{Feedback of findings and setup of targets}

Among the listed five processes, delay in initial assessment by the nurse was the only factor identified leading to delay in chemotherapy administration. Meeting was held with daycare physicians, nurses, and administrative staff and chemotherapy pharmacists regarding delay in initial assessment and how we could motivate the staff involved in this process to reduce it. Key areas for improvement were discussed and decided to improve delay in initial assessment by increasing the number of nurses assigned from three to six in the morning shift. A 12 -month period was agreed to implement and follow the changes.

\section{Review II to re-evaluate practices}

This review was done on 208 patients admitted for chemotherapy at daycare from March 1 to 31, 2016. It was done after doubling of number of nurses, to assess improvement in the initial assessment time. The extent to which the target set was met was fed back to the relevant staff.

Feedback of findings and setup of targets after Review II Based on the results, a decision was made to have a final round to close the audit loop.

\section{Review III to re-evaluate practices}

Review III was done on 287 patients admitted for chemotherapy at daycare between June 7 and August 25, 2016. To reduce the initial assessment time, this process was divided into two different areas. In initial assessment room, height and weight was checked and documented in the online computer system and patient sent to the assigned bed. Daycare physicians (medical officer or senior medical officer) assessed patient at the bedside while bedside nurse recorded the vital signs. This led to immediate start of chemotherapy order processing by the daycare physician. Subsequently, Review III of the audit was done to assess for any improvement in this process.

\section{Statistical analysis}

The analyses were performed using the IBM SPSS Statistics for Windows, Version 19.0 (IBM Corp. Released 2010. IBM SPSS Statistics for Windows, Version 19.0. Armonk, NY: IBM Corp.).

Comparisons of continuous variables among three audits were made by ANOVA, and post hoc test was performed to observe the difference between audits. Comparison of waiting time difference with three audits was plotted by box plot. Data are presented as boxplots; boxes represent the $25^{\text {th }}, 50^{\text {th }}$ (median), and $75^{\text {th }}$ centiles. All $P$ values were based on two-sided hypothesis testing and significance was set at a $P<0.05$.

\section{Results}

The initial assessment of practice (Review I) was based on 109 patients admitted for chemotherapy from April 14 to May 13, 2015. All timings of the processes were analyzed and checked against institutional made benchmarks [Table 1].

Table 1: Assessment of processes for delay in chemotherapy administration

\begin{tabular}{|c|c|c|c|c|c|c|}
\hline Process & $\begin{array}{l}\text { Institutional } \\
\text { benchmark }\end{array}$ & $\begin{array}{l}\text { Average time } \\
\text { (HH: MM) }\end{array}$ & $\begin{array}{l}\text { Maximum time } \\
(\mathrm{HH}: \mathrm{MM})\end{array}$ & $\begin{array}{l}\text { Minimum time } \\
(\mathrm{HH}: \mathrm{MM})\end{array}$ & $\begin{array}{l}\text { Compliance } \\
\text { percentage }\end{array}$ & $\begin{array}{c}\text { Noncompliance } \\
\text { percentage }\end{array}$ \\
\hline Arrival of patient time & $15 \mathrm{~min}$ & $0: 04$ & $0: 14$ & $0: 02$ & 100 & 0 \\
\hline Initial assessment by nurse & $15 \mathrm{~min}$ & $0: 14$ & $1: 10$ & 0:01 & 72.5 & 27.5 \\
\hline CPOE time & $2 \mathrm{~h}$ & $0: 51$ & 3:04 & $0: 02$ & 93.6 & 6.4 \\
\hline $\begin{array}{l}\text { Pharmacy dispatch time of } \\
\text { chemotherapy }\end{array}$ & $2 \mathrm{~h}$ & $1: 11$ & $3: 45$ & $0: 16$ & 92.6 & 7.4 \\
\hline $\begin{array}{l}\text { Administration time of } \\
\text { chemotherapy }\end{array}$ & $30 \mathrm{~min}$ & 0:06 & $0: 22$ & $0: 01$ & 100 & 0 \\
\hline
\end{tabular}

$\mathrm{CPOE}=$ Computer physician order entry 
Table 2: Comparative analysis of initial assessment by nurse after intervention

\begin{tabular}{|c|c|c|c|c|c|}
\hline Audit duration & $\begin{array}{l}\text { Average time } \\
\text { (HH:MM) }\end{array}$ & $\begin{array}{l}\text { Maximum time } \\
\text { (HH:MM) }\end{array}$ & $\begin{array}{l}\text { Minimum time } \\
(\mathrm{HH}: \mathrm{MM})\end{array}$ & $\begin{array}{l}\text { Compliance } \\
\text { percentage }\end{array}$ & $\begin{array}{c}\text { Noncompliance } \\
\text { percentage }\end{array}$ \\
\hline April 14 to May 13, 2015 & $0: 14$ & $1: 10$ & 0:05 & 72.5 & 27.5 \\
\hline March 1-31, 2016 & $0: 17$ & $1: 10$ & $0: 01$ & 55 & 45 \\
\hline June 7 to August 25, 2016 & $0: 13$ & $4: 08$ & 0:00 & 75 & 25 \\
\hline
\end{tabular}

All patients arrived in daycare within 15 min after admission. Thirty $(27.5 \%)$ patients took more than 15 min to have their initial assessment done. Seven $(6.4 \%)$ patients required more than $2 \mathrm{~h}$ to have their chemotherapy orders entered in CPOE system by the physician.

In $8(7.4 \%)$ patients, pharmacy took more than $2 \mathrm{~h}$ to dispatch chemotherapeutic drugs. Chemotherapy was administered in all patients within $30 \mathrm{~min}$. A compliance of more than $90 \%$ was seen in four out of five processes; in process of initial assessment of patient, compliance was only $72.5 \%$. These data are shown in Table 1 .

Review II is based on 208 patients admitted for chemotherapy from March 1 to 31, 2016, after increasing the number of nurses for initial assessment. The time required for initial assessment was within $15 \mathrm{~min}$ for 115 patients among the $208(55 \%)$ as shown in Table 2.

Review III is based on 287 patients admitted for chemotherapy from June 7 to August 25, 2016 after dividing the initial assessment process into two parts. The time required for initial assessment was within 15 min for 212 patients among the $287(75 \%)$ as shown in Table 2 .

There was $1.8 \mathrm{~min}(12.5 \%)$ decrease in the waiting time in comparison to Review I, II, and III.

The mean time required for initial assessment was $14.3 \pm 11.0 \mathrm{~min}$ (median [interquartile range (IQR)] 10 [6-20]) during Review I, $16.5 \pm 11.4$ min (median [IQR] 14 [8-25]) in Review II, and $12.5 \pm 11.0 \mathrm{~min}$ (median [IQR] 10 [5-18]) during Review III $(P<0.001)$ [Table 3]. Boxplots of waiting time difference in various audits are provided as Figure 1. The timelines of the audit are given in Table 4 .

\section{Discussion}

We report a first attempt to measure factors leading to delay in timely administration of chemotherapy from a developing country. The chemotherapy process involves team which include physician, nurses, and pharmacist, and delay can occur in any of these three areas. ${ }^{[1]}$ Delay in chemotherapy administration process is the major cause of dissatisfaction in patients and their attendants; we received verbal and written complaints from patients for delays in chemotherapy administration. Our study demonstrated that the initial assessment by the nurse is the leading cause of delay in chemotherapy administration. The institutional benchmark for this process is within 15 min of arrival of patient. We believe that by decreasing the delay in chemotherapy waiting time, we would be able to increase patient satisfaction and adjust more patients in the same time duration. This will also lead to increase in revenue in future as suggested by studies in the past. ${ }^{[7,12]}$
Table 3: Comparison of audit with different point in time $(\min )$

\begin{tabular}{lccccc}
\hline & Mean \pm SD & Median (IOR) & $P^{*}$ & Post hoc & $P$ \\
\hline Audit 1 & $14.3 \pm 11.0$ & $10(6-20)$ & $<0.001$ & $\begin{array}{c}\text { Audit 3 versus } \\
\text { audit } 1\end{array}$ \\
\hline Audit 2 & $16.5 \pm 11.4$ & $14(8-25)$ & \\
\hline Audit 3 & $12.5 \pm 11.0$ & $10(5-18)$ & \\
\hline SD=Standard deviation; IQR=Interquartile range
\end{tabular}

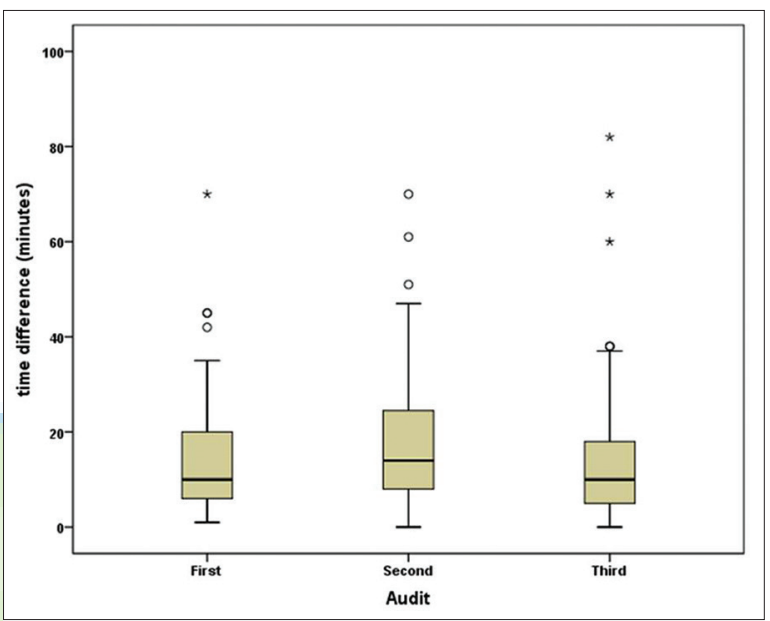

Figure 1: Waiting time of patients in different audits

At the second part of the audit after increasing the number of nurses, there was no time reduction in this process. However, after separating initial assessment process into two areas, in the third part of the audit, $75 \%$ of the patients completed their initial assessment within 15 min improving from $55 \%$.

The number of certified chemotherapy providers has dropped tremendously since 2014 as reported in a study by Liang. ${ }^{[13]}$ This is similar to our study where the number of chemotherapy providers has remained the same over the years despite the constant rise in number of patients. The total number of patients in daycare oncology is increasing each year, with data showing 15,978 patients receiving therapy in 2015 and 17,356 in 2016. In the studies similar to ours, a study which shows that the major cause of delay in chemotherapy is said to be time elapsed in registration, laboratory reports (especially if done on the same day), patient's assessment, and preparation of chemotherapy. ${ }^{[6,14]}$ Some of these processes were not assessed in our audit. We in the future propose adding these factors in addition to the five checkpoints performed in our study. In the few studies that have explored the setting of cancer care, long waiting times are frequently linked to dissatisfaction. Many factors such as the registration process, assessment of patients, laboratory results, and preparation of 
Table 4: Timelines of audit

\begin{tabular}{lll}
\hline Date & Person responsible for data collection & Task \\
\hline April 14 to May 13,2015 & Daycare doctors & $\begin{array}{l}\text { Documentation of time of } \\
\text { Arrival of patient into daycare } \\
\text { Initial assessment } \\
\end{array}$ \\
& & $\begin{array}{l}\text { Order entry in CPOE } \\
\text { Receiving chemotherapy from pharmacy } \\
\text { Initiation of administration of chemotherapeutic drugs by the nurse }\end{array}$ \\
\hline March 1-31, 2016 & Daycare doctors & Initial assessment time after increasing the nurses from 3 to 6 \\
\hline June 7 to August 25, 2016 & Daycare doctors & $\begin{array}{l}\text { Initial assessment time after dividing the process into two } \\
\text { separate areas }\end{array}$ \\
\hline
\end{tabular}

$\mathrm{CPOE}=$ Computer physician order entry

chemotherapy drugs consume a lot of time. Other factors such as decreased number of oncology trained medical and paramedical staff and availability of patient beds further contribute to the delays. Long waiting time and delays in chemotherapy administration increase patients' frustration and anxiety, hence resulting in patient dissatisfaction. ${ }^{[14]}$

\section{Future directions for research}

We propose to increase the number of personnel, treatment space, and equipment involved in chemotherapy administration. We also suggest that a day before the scheduled chemotherapy, all requirements such as patients' initial assessment and laboratory investigations are done and chemotherapeutic drug protocol entered in CPOE system. This would bring considerable reduction in waiting time of chemotherapy administration. An audit could then be done to evaluate the decrease in time of the process.

\section{Conclusion}

Our study demonstrated that by identifying reasons leading to delay in chemotherapy administration and bringing changes to rectify them, it was possible to reduce waiting time which we believe may translate into patient satisfaction.

\section{Acknowledgments}

The authors would like to thank all participating individuals. We would also like to acknowledge Dr. Syed Mohammad Mahmood and Dr. Seema Mithal Lakho who gave their intellectual input in study inception.

Financial support and sponsorship

Nil.

\section{Conflicts of interest}

There are no conflicts of interest.

\section{References}

1. Gesell SB, Gregory N. Identifying priority actions for improving patient satisfaction with outpatient cancer care. J Nurs Care Qual 2004; 19:226-33.

2. Anderson RT, Camacho FT, Balkrishnan R. Willing to wait?: The influence of patient wait time on satisfaction with primary care. BMC Health Serv Res 2007;7:31.

3. Pesata V, Pallija G, Webb AA. A descriptive study of missed appointments: Families' perceptions of barriers to care. J Pediatr Health Care 1999; 13: 178-82.

4. Lis CG, Rodeghier M, Gupta D. Distribution and determinants of patient satisfaction in oncology: A review of the literature. Patient Prefer Adherence 2009;3:287-304.

5. Thomas S, Glynne-Jones R, Chait I. Is it worth the wait? A survey of patients' satisfaction with an oncology outpatient clinic. Eur J Cancer Care (Engl) 1997;6:50-8.

6. Hendershot E, Murphy C, Doyle S, Van-Clieaf J, Lowry J, Honeyford L, et al. Outpatient chemotherapy administration: Decreasing wait times for patients and families. J Pediatr Oncol Nurs 2005;22:31-7.

7. Pearce S, Kelly D, Stevens W. 'More than just money' - Widening the understanding of the costs involved in cancer care. J Adv Nurs 2001;33:371-9.

8. Foote M. The importance of planned dose of chemotherapy on time: Do we need to change our clinical practice? Oncologist 1998;3:365-8.

9. Chavez-MacGregor M, Clarke CA, Lichtensztajn DY, Giordano SH. Delayed initiation of adjuvant chemotherapy among patients with breast cancer. JAMA Oncol 2016;2:322-9.

10. Joseph N, Clark RM, Dizon DS, Lee MS, Goodman A, Boruta D Jr., et al. Delay in chemotherapy administration impacts survival in elderly patients with epithelial ovarian cancer. Gynecol Oncol 2015; 137:401-5.

11. Aziz A. Innovation in chemotherapy administration process. Indian J Cancer 2016;53:331-2.

12. Kallen MA, Terrell JA, Lewis-Patterson P, Hwang JP. Improving wait time for chemotherapy in an outpatient clinic at a comprehensive cancer center. J Oncol Pract 2012;8:e 1-7.

13. Liang JY. Reducing Wait Time of Chemotherapy and Biotherapy Administration to Inpatients by Increasing the Numbers of Chemotherapy Providers: University of San Francisco; 2015.

14. Moss L, Kamal A, Sutton L. Causes of chemotherapy infusion delays: Results of a time study in an academic cancer clinic in the community. J Clin Oncol 2012;30(34 suppl):251. 